\title{
Una aproximación al concepto de puesta en valor turística del patrimonio industrial
}

\section{A closer approach to the concept of industrial heritage from a touristic point of view}

Antonio J. Palacios García

Carmen Hidalgo Giralt

Universidad Autónoma de Madrid

Resumen: La "valorización" o "puesta en valor turística" del patrimonio industrial es un término reciente aunque frecuentemente utilizado en la literatura científica actual. No obstante, son escasas las reflexiones existentes sobre su verdadero alcance y significado; hecho que genera confusiones y graves problemas conceptuales. Por ello, se ha creído conveniente revisar este concepto atendiendo a la bibliografía y documentación existente procedente tanto de los organismos internacionales como de los especialistas en la materia.

Palabras clave: Desarrollo turístico. Puesta en valor turístico. Patrimonio industrial. Turismo industrial.

Abstract: The "tourist valorization" of industrial heritage sites is a concept that has entered scientific debate only recently, and now reaches out for a broader public. However, more profound reflections on the range and real value of the concept are still scarce and limited, so that very often serious conceptual problems arise. For this reason, a bibliography review has been performed to analyze some aspects related to the increasing tourist value of industrial heritage.

Keywords: Tourism development. Tourism value. Industrial heritage. Industrial tourism.

Resumo: A valorização turística do patrimônio industrial é um conceito recente, ainda que frequentemente seja utilizado na literatura científica atual. Contudo, são escassas as reflexões existentes sobre seu verdadeiro alcance e significado. Este fato gera confusões e graves problemas conceituais. Por isso, acredita-se ser conveniente revisar este conceito, atendendo à bibliografia e documentação existente procedente tanto de organismos internacionais como dos especialistas no campo.

Palavras-chave: Desenvolvimento turístico. Valorização turística. Patrimônio industrial. Turismo industrial. 


\section{INTRODUCCIÓN}

Desde el último tercio del siglo XX se lleva produciendo, mayoritariamente en el continente europeo, el cierre de numerosos espacios industriales como consecuencia de la crisis del sector lo que ha generado graves efectos desestructurantes (desempleo, inmigración, ruinas industriales, etc.) en aquellas poblaciones excesivamente dependientes de esta actividad. Paralelamente a este proceso de reconversión ha surgido una conciencia social que lucha por salvaguardar aquellos elementos industriales, tanto materiales como inmateriales, propios de una actividad que ya pertenece al pasado. La puesta en valor turística del patrimonio que se ha quedado sin uso es una oportunidad más de desarrollo que se integra en este proceso de diversificación. Es, precisamente, el turismo, concebido como un elemento dinamizador del territorio, uno de los instrumentos más recurrentes al respecto. Aunque el concepto de valorización turística del patrimonio es manejado habitualmente por los especialistas en patrimonio industrial, sus bases conceptuales están escasamente estudiadas. Por ello, se ha considerado conveniente realizar en este artículo una aproximación conceptual a su significado atendiendo a tres elementos claves: el origen del patrimonio industrial, la noción de valorización turística de dicho patrimonio $\mathrm{y}$ las implicaciones del turismo industrial en la actualidad.

\section{UNA APROXIMACIÓN AL PATRIMONIO INDUSTRIAL DESDE EL PUNTO DE VISTA DE LAS ORGANIZACIONES INTERNACIONALES}

Keneth Hudson (1979, p. 2) fue el primer investigador en desarrollar en 1964 un corpus teórico sobre esta disciplina. Definió la arqueología industrial como "el descubrimiento, catalogación y estudio de los vestigios del pasado industrial y de las comunicaciones" cuyo objeto de estudio, entre otros muchos, se basaba en "la reconstrucción del contexto físico en el que se desarrollaba el trabajo". Para ello, subrayaba la necesidad de hacer uso de la metodología arqueológica así como sus técnicas de trabajo (FORNER, 1989, p. 22). La arqueología industrial (PINARD, 1987; FORNER, 1989; BENITO DEL POZO, 2002) abrió las puertas a otras muchas disciplinas que interesadas por el conocimiento del patrimonio industrial comenzaron a profundizar desde perspectivas diferentes (JACOMY, 1984; CAPEL, 1996; VIAENE, 1998; VIÑUALES, 2004; CAÑIZARES, 2008).

Por su parte, los organismos internacionales como la UNESCO, el ICOMOS o la propia Unión Europea también comenzaron a trabajar en este campo dando lugar al mejor corpus teórico sobre patrimonio industrial que existe en la actualidad. En este sentido es de destacar la labor del Comité Internacional para la Conservación del Patrimonio Industrial (TICCIH), una institución fundada en 1978 que asesora en materia de patrimonio industrial al ICOMOS $^{1}$, a la UNESCO y al Consejo de Europa. Uno de los principales documentos elaborados por el TICCIH es la "Carta de Nizhny Tagil sobre el Patrimonio Industrial" (2003), un documento de referencia para los países miembros. En el punto primero se desarrolla una definición de patrimonio industrial entendiendo como tal "a los restos de la cultura industrial que poseen un valor histórico, tecnológico, social, arquitectónico o científico. Estos restos consisten en edificios y maquina-

1 Órgano especializado en materia de conservación, protección, rehabilitación y mejora de monumentos, grupos de edificios, sitios y paisajes históricos. 
ria, talleres, molinos y fábricas, minas y sitios para procesar y refinar, almacenes y depósitos, lugares donde se genera, se transmite y se usa energía, medios de transporte y toda su infraestructura, así como los sitios donde se desarrollan las actividades sociales relacionadas con la industria, tales como la vivienda, el culto religioso o la educación". Desde un punto de vista cronológico, muestra una clara preferencia por los restos que abarcan desde la Revolución Industrial hasta nuestros días: "el periodo histórico de principal interés se extiende desde el principio de la Revolución Industrial, la segunda mitad del siglo XVIII, hasta la actualidad incluida. Si bien también se estudian sus raíces preindustriales y protoindustriales".

En dicho documento se apuesta por la conservación "in situ" 2 como el método más adecuado para proteger el patrimonio industrial. Los museos especializados, los sitios industriales y las rutas temáticas se presentan como excelentes medios para asegurar la conservación del patrimonio industrial al mismo tiempo que fomentan la difusión pública y el traspaso de conocimiento: "el interés y el afecto público por el patrimonio industrial y la apreciación de sus valores son las formas más seguras de conservarlo. Las autoridades públicas deben explicar activamente el significado y el valor de los sitios industriales mediante publicaciones, exposiciones, televisión, Internet y otros medios, proporcionando acceso sostenible a sitios importantes y promoviendo el turismo en áreas industriales". Por otro lado, es de destacar que el TICCIH firmó en el $2000^{3}$ un acuerdo de colaboración con ICOMOS a través del cual se estableció un vínculo de cooperación para constituir grupos mixtos de trabajo en

\footnotetext{
2 La conservación "in situ" propone "contextualizar el medio físico de los objetos" (HERNÁNDEZ HERNÁNDEZ, 1998, p. 79 ), es decir, favorecer que los bienes se conserven, protejan y difundan en el lugar donde se localizan teniendo en cuenta que el entorno que les rodea también es un elemento "museable". 3 Disponível em: < http://www.mnactec.com/ticcih/ >.
}

materia de patrimonio industrial. El TIC$\mathrm{CIH}$ se presenta como el cuerpo consultivo en esta materia $y$, entre sus actuaciones, destaca la elaboración de informes técnicos para el programa de la UNESCO de la Lista del Patrimonio Mundial en relación a aquellos bienes culturales de carácter industrial.

La UNESCO no ha realizado demasiadas aportaciones teóricas al concepto de patrimonio industrial. Su importancia radica en un plano más práctico, concretamente, en la inscripción del patrimonio industrial dentro de la Lista del Patrimonio Mundial. Entiende el patrimonio industrial como un ejemplo del desarrollo tecnológico del ser humano incluyendo como tal "a los triunfos sociales y de ingeniería engendrados por las nuevas tecnologías: ciudades minero-industriales, canales, líneas férreas, puentes y otras formas de transporte e ingeniería" ${ }^{4}$. En general, distingue cuatros sitios diferentes: lugares de producción, minas, medios de comunicación y sitios de ingeniería arqueológica. Utiliza, por lo tanto, un concepto muy amplio de patrimonio industrial puesto que no impone límites cronológicos al tratamiento del mismo, de hecho, en la Lista del Patrimonio Mundial, se encuentran inscritos bienes de periodos dispares que abarcan desde de las minas romanas de Las Médulas (España) hasta la ciudad de Potosí (Bolivia), pasando por el poblado industrial de New Lanark del siglo XVIII (Reino Unido) o los ferrocarriles de montaña de la India que comenzaron a utilizarse a principios del siglo XX.

Por su parte, la relación de la Unión Europea con el patrimonio minero-industrial se centra fundamentalmente en la concesión de subvenciones con el fin de recuperar, proteger y difundir los bienes culturales teniendo en cuenta acciones de cooperación y coordinación internacional

\footnotetext{
4 Disponível em: < http://whc.unesco.org/sites/industrial.
} htm $>$. 
dentro de las líneas de actuación señaladas por el Tratado de Maastritcht ${ }^{5}$ (1992). En este sentido varios son los programas de actuación que han intervenido en el campo del patrimonio industrial. Tal es el caso de los Proyectos Pilotos Comunitarios a través de los cuales se rehabilitaron en España (1991) cuatro conjuntos industriales: la Cooperativa agrícola i Caixa Agraria en Espluga de Francolí (Tarragona); el antiguo dique del Astillero de Puerto Real (Cádiz); la Fábrica de Harinas "La Horadada" en Mave (Palencia); y, por último, la Fábrica Aymerich, Amat y Jove en Tarrasa (Barcelona). De todos ellos, a los tres últimos se les ha dotado de usos turísticos-culturales. También hay que destacar al respecto los Fondos Estructurales Europeos que con iniciativas como el Fondo Social Europeo, el programa Raphaël o RESIDER, han favorecido proyectos como, por ejemplo, el Museo de la Minería del Entrego o la Escuela Taller de Arqueología Industrial de Bustiello, ambos en Asturias (BENITO DEL POZO, 1996).

\section{LA VALORIZACIÓN TURÍSTICA DEL PATRIMONIO INDUSTRIAL: ALCANCE Y SIGNIFICADO SEGÚN LAS APORTACIONES BIBLIOGRÁFICAS}

La puesta en valor del patrimonio cultural se concibe como la recuperación y rehabilitación de los bienes culturales con el objetivo de dotarle de nuevos usos (turísticos, culturales, deportivos, residenciales, etc.) y reinsertarlo nuevamente en el tejido social para asegurar su protección. Se ajusta a lo que hoy día se entiende como conservación integrada, es decir, el resul-

5 En el Tratado de Maastricht se regulan, entre otras, la política de la Unión Europea en materia cultural. La línea principal del documento se basa en la subsidiaridad, en la concesión de ayudas para desarrollar acciones de conservación y protección de los bienes culturales seleccionados por los países miembros. tado de la acción conjunta de técnicas de conservación, de investigación y adaptación de ese patrimonio a las necesidades de la sociedad del momento. A partir de los años noventa diferentes autores comenzaron a reflexionar sobre la puesta en valor turística del patrimonio industrial. Aunque no existe un modelo teórico concreto sobre la valorización de estos bienes culturales, a través del análisis de las iniciativas llevadas a cabo por los diferentes países, se pueden observar cuales son los planteamientos seguidos por los mismos y sacar conclusiones generales al respecto.

\section{Europa, continente pionero en la valorización turística del patrimonio industrial}

El Reino Unido ha sido un país pionero en el tratamiento del patrimonio industrial desde un punto de vista teórico y práctico atendiendo a diferentes temáticas. Destacan especialmente las aportaciones de Denise Cole (2004, p. 486), profesora de la Universidad Metropolitana de Londres, que analiza los diferentes aspectos de la gestión de los recursos turísticos industriales en Gran Bretaña (número de visitantes y empleados; fuentes de ingresos y niveles de beneficio; productos ofrecidos a cada visitante, etc.) como parte fundamental de la puesta en valor turística de los mismos. Por otro lado, profundiza en los vínculos existentes entre el turismo industrial y la sociedad, el medioambiente y las economías locales. De igual modo, defiende el concepto de conservación "in situ" como medio para integrar a las sociedades locales en los procesos de creación de productos (COLE, 2004, p. 481) y siguiendo los planteamientos de otros autores como, por ejemplo, Edwards \& Llurdés i Coit (1996, p. 343) o Jansen-Verbeke (1999, p.73), apuesta por evitar la regeneración de los 
paisajes a estados preindustriales con el fin de favorecer la conservación de los vestigios industriales del pasado (COLE, 2004, p. 483).

Consciente de la necesidad de ordenar las infraestructuras turísticas de un territorio, Jansen-Verbeke (1999, p. 80) se interesa por la reconversión de las regiones mineras en sitios industriales de interés turístico centrándose en propuestas concretas de reutilización. Partiendo de otras experiencias europeas como, por ejemplo, el Emscherpark ${ }^{6}$ en Alemania, la autora propone para el caso belga de la región minera de Limburg, diferentes estrategias en función de las características de los núcleos. Las acciones abarcan desde la creación de un museo al aire libre, hasta la apertura de un gran centro comercial y de ocio, pasando por un parque deportivo o un centro de información turística. En el caso belga resultan también interesantes las reflexiones de Viaene (1998, p. 55) sobre el patrimonio hullero nacional y su puesta en valor atendiendo a criterios de conservación integrada.

En el ámbito de los países europeos mediterráneos hay que señalar que la bibliografía científica es más escasa en cuanto a que cuentan con una menor tradición en el estudio del patrimonio minero-industrial. Sin embargo, en los últimos años se evidencia un incremento considerable de la misma. En Portugal, por ejemplo, hay que destacar las aportaciones de Lopes (1998, p. 41) el cual ha realizado una revisión de las principales iniciativas de puesta en valor del patrimonio minero-industrial enmarcándolas dentro de una corriente de defensa del patrimonio cultural que surgió a finales de los años setenta. Las experiencias lusas en la actualidad son escasas y se relacionan más con el patrimonio industrial

6 Situado en la cuenca carbonífera del Ruhr, la reconversión de esta zona industrial ha consistido en la puesta en marcha de 120 proyectos destinados a la regeneración del paisaje, mejora del medio ambiente y el desarrollo de recursos culturales en atracciones turísticas (JANSEN-VERBEKE,1999). como es el caso del Ecomuseo Municipal do Seixas (FILIPE, 2003, p. 80). En Italia, Máximo Preite (2002, p. 15) es uno de los principales teóricos de la materia. Especializado en la Toscana, analiza diferentes iniciativas de valorización turística como, por ejemplo, el Parque Arqueo-Minero de San Silvestre, el Parque Museo Minero de Abadía San Salvatore o el Parque de las Colinas Metalíferas, haciendo especial hincapié en la musealización del territorio.

\section{América, un continente cada vez más concienciado con la valorización turística del patrimonio industrial}

En comparación con Europa, Norteamérica posee una corta tradición industrial. No obstante, existe una importante conciencia por valorizar turísticamente el patrimonio industrial desde finales de los años setenta con la creación de la asociación estadounidense Historic American Enginering Record (HAER) cuyo objetivo consiste en detectar los principales sitios industriales del país. Por otro lado, resultan bastante significativos los estudios canadienses que, desde un punto de vista territorial, plantean la utilización de los antiguos recursos industriales con fines turísticos. Perreault (1996, p. 31) analiza el pasado minero-industrial de la región Abitibi-Témiscamingue, el impacto humano y medioambiental así como las atracciones turísticas centradas en los recursos mineroindustriales especialmente la Ciudad del Oro y el Museo Regional de las Minas de Malartic. Por su parte, Fritz-Nemeth \& Lundgren (1996, p. 23) establecen un inventario de las localizaciones industriales dividida en tres categorías con el fin averiguar el índice de utilidad turística y establecer las estrategias de desarrollo más adecuadas.

En el caso de Iberoamérica, es de destacar que, desde finales de la década de los 
noventa, se está incrementando considerablemente la bibliografía relacionada con el patrimonio industrial desde el punto de vista de la conservación, rehabilitación y puesta en valor. Viñuales (2004) realiza una revisión general del desarrollo industrial en Iberoamérica desde el siglo XIX hasta finales del XX señalando los diferentes factores de evolución y crisis del sector. Analiza las tendencias de conservación del patrimonio industrial que se están desarrollando en el sur del continente americano desde finales de los años noventa y que han llevado a dotar de diferentes usos (culturales, comerciales, educativos, etc.) a antiguas infraestructuras industriales como, por ejemplo, las fábricas textiles de Tlaxcala (México), convertidas en la actualidad en hoteles y colonias de vacaciones, $\mathrm{o}$ la fábrica de San Pablo de Porto Alegre (Brasil) rehabilitada como un espacio cultural. Consciente de la dificultad de conservar las áreas industriales diseminadas por el territorio frente a los espacios situados en áreas urbanas o periurbanas, considera necesario vincular la rehabilitación del patrimonio al espacio territorial que le rodea así como con iniciativas similares como medio para complementar la rentabilidad económica, cultural y social de este tipo de experiencias.

En esta línea se sitúa el grupo de investigación argentino TU.CU.NA ${ }^{7}$ (2003) vinculado con el desarrollo turístico de la provincia de Tucumán. Plantean el diseño de una ruta turística que, basada en el aprovechamiento de los recursos del patrimonio industrial azucarero, reactive la economía de la zona y, al mismo tiempo, proteja el patrimonio cultural y natural localizado en la región. En cambio, en el caso de Cuba, la bibliografía tiende a poner de manifiesto la riqueza del país en este tipo de patrimonio. En general son documentos

7 Grupo de investigación multidisciplinario perteneciente de la Universidad Nacional de Tucumán. que desarrollan una aproximación histórica a los diferentes ejemplos de patrimonio industrial haciendo hincapié tanto en su origen como evolución y proceso de desactivación productiva ${ }^{8}$. Hay que destacar las propuestas que se realizan en el área de Santa Fe en cuanto a la combinación del turismo cultural y natural (FLEITES, 1998, p. 19) así como los intentos del gobierno por proteger el patrimonio industrial mediante la "Ley de Protección al Patrimonio Cultural" y la "Ley de los Monumentos Nacionales y Locales" (PERERA, 1998, p. 5).

Por lo tanto, aunque el proceso de valorización turística del patrimonio industrial en general ha sido tardío en comparación con otros tipos de bienes culturales, en los últimos años se ha incrementado considerablemente la bibliografía al respecto tanto en el ámbito europeo como americano. En general no hay grandes diferencias entre ambos continentes, comparten estrategias como la conservación "in-situ" y la importancia del territorio para el patrimonio industrial como elemento potencialmente museable.

\section{El concepto de turismo industrial en la actualidad: tres modalidades diferentes}

La puesta en valor turístico del patrimonio industrial trae consigo el desarrollo de una nueva modalidad turística, el turismo industrial. En la actualidad, este concepto se aplica a tres modalidades diferentes: la visita a empresas que se encuentran en activo en la actualidad, la visita al patrimonio industrial inactivo y, por último, una combinación de las anteriores.

8 Varios son los ejemplos a los que se hacen referencia tales como la Cervecería Pedro Marrero "La Tropica" (HEVIA, 1998) o el ingenio azucarero "Tahoro" y su entorno (FLEITES, 1998). 


\section{El turismo industrial, la visita a empresas en activo}

Francia es, quizás, el país europeo que más producción científica ha publicado relacionada con el turismo industrial en la modalidad de visitas a empresas en activo (MARAVAL, 1998; FLACHS, 1998; BÖHMER 1998; COUSIN, 1998), hecho que no es sorprendente si se tiene en cuenta su dilatada experiencia. De hecho, durante las primeras décadas del siglo XX, la planta de Peugeot de Sochaux o la fábrica de Kronenbourgh de Estrasburgo ya abrían sus puertas a los visitantes. El desarrollo del turismo industrial se suele integrar dentro de una corriente muy amplia que se relaciona con el turismo científico y técnico (CORNU, 1998, p. 15; COUSIN, 1998, p. 6). Este tipo de turismo tiene como objetivo fundamental fomentar la visita a "ecomuseos, parques científicos o técnicos, empresas, fábricas y lugares de producción artesanal o industrial" (MASSÉ, 1998, p. 26) bajo una doble perspectiva, didáctica y promocional. Al mismo tiempo que se pretende dar a conocer las empresas tecnológicas, industriales y científicas a los visitantes, se utilizan estas empresas como instrumentos para promocionar un territorio y generar actividad económica como es el caso de la región de $\operatorname{Cognac}^{9} \mathrm{o}$ de Nord-Pas-de-Calais ${ }^{10}$.

El turismo industrial concebido como la visita a empresas operativas está tomando mucha fuerza en otros países tal y cómo refleja el proyecto internacional "Indus-

\footnotetext{
9 La Oficina de Turismo de Cognac registró en 1997 la llegada de más de 300 grupos de 20 a 50 personas cada uno. Este éxito de visitantes se debió al desarrollo de numerosas iniciativas turísticas de naturaleza muy diversa que abarcacaba desde la visita a la Tonelería Vicard hasta una degustación de licor, pasando por un paseo en barco por la proximidad a las viñas o por la Vidriería Saint Gobain. (GOUBARD, 1998).

10 En el caso de Nord-Pais-de-Calais, el Comité Regional de Turismo desarrolló un proyecto piloto entre 1997 y 1998 con el objetivo de atraer un mercado turístico centrado en la visitas a casi una veintena de empresas de naturaleza técnico-industrial que se sigue desarrollando en la actualidad (LECLERCQ, 1998).
}

trial tourism: opportunities for city and enterprise" llevado a cabo por el European Institute for Comparative Urban Research (EURICUR) y la Universidad Erasmus de Rótterdam. En este estudio se analizan seis ciudades donde se ha detectado la implantación del turismo industrial, Wolfsburgo y Colonia (Alemania), País de la Loire (Francia), Turín (italia), Shangai (China) y Rótterdam (Holanda), y cuáles son los factores de su éxito. El estudio demuestra como este tipo de actividad puede ser un "instrumento de mejora de las ciudades y las industrias, estimulando la competitividad de las ciudades y regiones (como destino turístico y localización empresarial) y fomentar las relaciones entre las empresas y la sociedad" (OTGAAR et. al., 2008). Aunque en este proyecto se señala la existencia de un turismo industrial articulado en el patrimonio, aquí es concebido como la visita a una empresa que se encuentra en activo, ya sea pública o privada, con el fin de dar a conocer la compañía y los procesos productivos que se desarrollan en la misma.

\section{El turismo industrial, el conocimiento del patrimonio industrial en desuso}

La producción científica vinculada exclusivamente al turismo industrial como el conocimiento de antiguos espacios industriales en desuso es extraordinariamente escasa. No obstante, destaca la Asociación IN FOLIO ${ }^{11}$ que afirma que éste se basa en la valorización turística de aquellos lugares industriales que no se encuentran en actividad y que han sido acondicionados como ecomuseos, museos, sitos históricos, museos del territorios, etc. (DAMIEN e SOBRY, 2001, p. 21).

11 Disponível em: < http://www.in-folio.org/tourisme-dedecouverte-economique.htm $>$. 
Varios son los investigadores españoles que han trabajado sobre esta modalidad turística. Destacan las aportaciones de Llurdés i Coit (1994, p. 92), uno de los primeros geógrafos en tratar este tema. A lo largo de varios trabajos, expuso las diferentes características del turismo basado en patrimonio industrial y analizó sus causas y consecuencias. Define esta modalidad de turismo como "la promoción y explotación de unas antiguas instalaciones mineras e industriales de cara a la atracción de un cierto segmento de visitantes y turistas" y basa su origen, entre otros, en la saturación de los mercados turísticos tradicionales (EDWARDS; LLURDÉS I COIT, 1996) y en una modificación de los gustos de los turistas.

Valenzuela (2003, p. 409 y 435) revisa las principales experiencias de recuperación del "patrimonio utilitario" llevadas a cabo con fines turísticos tanto en España como en Europa. Realiza una referencia concreta al turismo minero que lo concibe como aquella vertiente del turismo industrial que se centra en los recursos de tipo minero-industrial y que da lugar a un perfil de turista que busca "ofertas más activas e imaginativas" y "preocupadas por la calidad del destino turístico". Señala, sin embargo, que aunque este tipo de turismo puede ser una herramienta de diversificación del turismo y de regeneración económica local, "éstos no deben cerrarse antes los retos, los problemas y las necesarias cautelas con las que afrontar cuantas dimensiones les afectan, sin deslumbramientos ni espejismos deformadores".

Por su parte, Pardo (2004, p. 29) define el turismo industrial de tipo patrimonial como aquel en el que las visitas se centran en "fábricas abandonadas, con reutilización museística o con instalaciones de algún centro artístico o interpretativo". También incluye como tal "las piezas sueltas conservadas, como máquinas de vapor, chi- meneas o territorios más o menos amplios caracterizados por la actividad en otras fases de industrialización". Al igual que los autores citados anteriormente, señala la importancia de esta actividad para la recuperación económica de aquellas antiguas zonas industriales paralizadas por la crisis del sector.

\section{El turismo industrial, el descubrimiento de las actividades industriales pasadas y actuales}

Respecto a la última modalidad establecida, varios son los autores que, en el ámbito internacional, aúnan las dos aproximaciones mencionadas del concepto de turismo industrial. Tal es el caso de Beaudet \& Lundgren (1996, p. 17) que, en un estudio sobre el turismo industrial en Canadá, lo definen como "una actividad que descubre el patrimonio industrial, el de las empresas en actividad, el de los lugares de interpretación de la técnica, del trabajo y los trabajadores y de los centros de investigación industrial". Analizan los factores del desarrollo de este tipo de turismo (desindustrialización, pérdida de conocimientos y técnicas de trabajo, etc.), señalan sus antecedentes en la región de Québec y subrayan los ámbitos que abarca el turismo industrial (tecnología, cultura científica, arqueología industrial, etc.).

Siguiendo esta misma línea se sitúa el grupo de investigación GIREST ${ }^{12}$ de la Universidad de Lille (Francia). En su estudio sobre el turismo industrial en Francia (DAMIEN; SOBRY, 2001) define esta modalidad como el conjunto de prácticas turísticas donde los motivos de desplazamiento son los mundos de trabajo tanto pasados como presentes y futuros, es decir, el conjunto de técnicas, organización

12 Grupo interdisciplinario de investigación en deporte y turismo. 
y culturas ligadas al trabajo. Además en esta investigación se subrayan los aspectos positivos del turismo industrial en cuanto a desarrollo local se refiere (creación de empleo, integración territorial, sinergia entre actores públicos y privados, implantación de sistemas de calidad y formación, etc.). Resulta especialmente interesante el análisis de las formas y contenidos del turismo industrial combinando la visita al patrimonio en activo y no activo y la organización de visitas turísticas organizadas y no organizadas.

\section{LA VALORIZACIÓN TURÍSTICA DEL PATRIMONIO INDUSTRIAL EN ESPAÑA}

España, aunque se ha incorporado tarde al estudio del patrimonio industrial ha desarrollado en los últimos años una interesante bibliografía sobre el tema con enfoques multidisciplinares. El Estado, consciente del valor de este patrimonio, ha elaborado un completo programa enfocado a su salvaguarda. En lo que respecta especialmente a su valorización turística, también se está desarrollando una importante bibliografía aunque basada en casos concretos y sin ningunas pautas generales.

\section{El Plan Nacional de Patrimonio Industrial, un referente para el patrimonio industrial en España}

La Ley de Patrimonio Histórico Español de 1985 desarrolla un concepto muy amplio del concepto de patrimonio cultural lo que permite tratar aquellos elementos relacionados con el patrimonio industrial aunque no se establezca en dicha normativa jurídica un tratamiento específico para el mismo ${ }^{13}$. Por ello, el Estado consciente de la necesidad de preservar, conservar y recuperar el patrimonio industrial ante el grave deterioro que sufre puso en marcha en el año 2000 el Plan Nacional de Patrimonio Industrial a través de la Dirección General de Bellas Artes y Bienes Culturales y el Instituto del Patrimonio Histórico Español. El patrimonio industrial es definido en el Plan como el "conjunto de elementos de explotación industrial, generado por las actividades económicas de cada sociedad que responde a un determinado proceso de producción y a un sistema tecnológico concreto caracterizado por la mecanización dentro de un determinado sistema socioeconómico". En él se diferencian tres tipos de elementos minero-industriales:

- Elementos aislados por su naturaleza o por la desaparición del resto de sus componentes pero que por su valor histórico, arquitectónico, tecnológico, etc., son testimonio suficiente de una actividad

\begin{tabular}{l|c|c}
\hline Tipología & \multicolumn{1}{c}{$\begin{array}{c}\text { Actividades turísticas } \\
\text { organizadas }\end{array}$} & $\begin{array}{c}\text { Actividades turísticas no } \\
\text { organizadas }\end{array}$ \\
\hline Patrimonio activo & Empresas abiertas a la visita & $\begin{array}{c}\text { Empresas ocasionalmente abiertas a } \\
\text { la visita }\end{array}$ \\
\hline $\begin{array}{l}\text { Patrimonio } \\
\text { inactivo }\end{array}$ & $\begin{array}{c}\text { Ecomuseos, sitios mineros, } \\
\text { museos técnicos, etc. }\end{array}$ & $\begin{array}{c}\text { Paseos ocasiones a fábricas o } \\
\text { elementos abandonados }\end{array}$ \\
\hline
\end{tabular}

Cuadro 1. Formas y contenidos del turismo industrial según GIREST

Fuente: Damien \& Sobry (2001)

13 Inventario General de Bienes Industriales Españoles, Declaración de Bien de Interés Cultural, Proyectos de Ejecución, Estudios previos al Plan Director y Planes Directores. 
industrial a la que ejemplifican.

- Conjuntos industriales en los que se conservan todos los componentes materiales y funcionales y su propia articulación. Constituyen una muestra coherente y completa de una determinada actividad industrial.

- Paisajes industriales en los que se conservan, visibles, todos los componentes esenciales de los procesos de producción de una o varias actividades industriales, incluidas, las transformaciones del paisaje ocasionadas por dichas actividades.

El Plan Nacional de Patrimonio Industrial hace especial hincapié en la obligación que tiene el Estado de proteger, conservar y recuperar el patrimonio industrial que se encuentra en un claro proceso de desaparición debido a la escasa consideración que ha tenido históricamente. El objetivo del plan consiste en seleccionar una serie de bienes por cada Comunidad Autónoma que representen en su conjunto las diferentes etapas de industrialización y dotarlas de una serie de figuras instrumentales para asegurar la correcta ejecución del mismo . Hasta el momento han sido seleccionados 49 bienes de patrimonio industrial localizados en 14 Comunidades Autónomas diferentes (Figura 1), entre los que destacan, por ejemplo, las Minas de Riotinto (Huelva) o el Paisaje Minero de Puertollano (Ciudad Real).

Por otro lado, varios son los especialistas españoles que han desarrollado definiciones del concepto de patrimonio industrial. En primer lugar, hay que destacar las aportaciones de Álvarez Areces (2001, p. 13) el cual subraya que el patrimonio industrial "se puede considerar como un componente importante de la cultura material de la sociedad industrial basada en el modo de producción mercantil capitalista". No impone límites geográficos

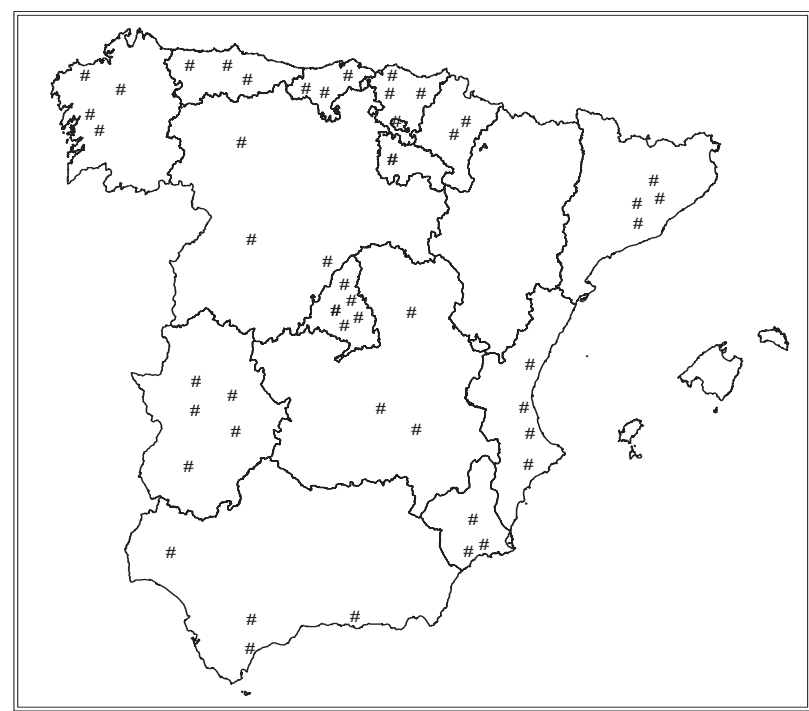

Figura 1 - Mapa con bienes seleccionados por el Plan Nacional de Patrimonio Industrial

Fuente: Elaboración propia según los datos del Plan Nacional de Patrimonio Industrial (2008)

pero sí considera que la delimitación de su ámbito temporal puede reducirse a la "etapa preindustrial y protoindustrial" finalizando en el momento que "una tecnología deja de ser utilizada, queda obsoleta y es reemplazada por otra". Considera que el patrimonio industrial está constituido por "aquellos bienes que han sido parte de una revolución tecnológica y socioeconómica que provocó cambios notables en nuestra sociedad". De igual modo, como ocurre en el caso del patrimonio cultural, señala la importancia de su estudio, protección y conservación bajo una doble vertiente, por un lado, la necesidad de salvaguardar sus valores para las generaciones futuras, $\mathrm{y}$, por otro, desarrollar planes de actuación que, incluyendo al patrimonio industrial, favorezca el desarrollo sostenible local.

Siguiendo esta misma línea teórica aunque sin profundizar tanto en el alcance y significado del patrimonio industrial, hay que destacar las aportaciones de Llurdés i Coit $(1999$, p. 148) que entiende como tal a "todos aquellos vestigios materiales y culturales propios de la civilización industrial". Ofrece una visión muy amplia 
del concepto al incluir bienes materiales e inmateriales aunque, tal y como sucede con Álvarez Areces, limita su extensión al ámbito del periodo industrial aunque no de una forma tan restrictiva. El autor se centra fundamentalmente en aspectos relacionados con la reutilización del patrimonio industrial como medio para "reactivar la economía local, encontrar nuevas vías de desarrollo y generación de riqueza", entre los que destaca el turismo.

Casanelles (1998), por su parte, concibe el patrimonio industrial como "aquellos bienes relacionados con la producción, que son testimonio y objeto de estudio de una era pasada, y tienen como valor añadido que fueron los protagonistas de una gran revolución social y económica que cambió la sociedad hasta desembocar en la sociedad post-industrial actual". Al igual que los autores anteriores tiene una visión muy amplia de los bienes industriales y establece limitaciones cronológicas al patrimonio industrial. Como novedad hay que destacar que introduce acotaciones espaciales al señalar que "esta revolución no se desarrolló homogéneamente por todas partes sino que hubo regiones y localidades que tuvieron un protagonismo específico sobre las otras". Por un lado, dota al patrimonio de una serie de valores históricos y económicos que justifican su protección, conservación y reutilización, lo que le permite incidir en la idea de la "musealización"14 de los espacios industriales como medio de salvaguardar aquellos elementos más significativos que puedan servir desde un punto de vista didáctico para comprender "una parte de la historia social y económica

14 Esta política basada en la musealización de los espacios minero-industriales ha sido puesta en práctica a través del Museu de la Ciencia i de la Técnica de Catalunya a través de lo que se conoce el sistema mNACTEC, la agrupación de un conjunto de museos localizados en toda la Comunidad Autónoma centrados en una temática concreta. Para más información consúltese: < http://www.mnactec.com >. de una época" (CASANELLES, 1998, p. 17). Frente a las definiciones apuntadas es de destacar el concepto que utiliza Valenzuela (2003, p. 401) en relación con el patrimonio industrial puesto que maneja un término original denominado "patrimonio utilitario" con el que designa a todos aquellos "bienes patrimoniales surgidos de actividades productivas, en cuya concepción y funcionamiento prevaleció la finalidad económica por encima de las consideraciones estéticas, aunque en ocasiones éstas pudieran existir".

\section{La valorización turística del patrimonio industrial}

En los últimos años, son numerosas las experiencias de recuperación del patrimonio industrial desde un punto de vista turístico que se están llevando a cabo en España. La producción científica no es ajena a este hecho de tal manera que es muy numerosa la bibliografía que analiza este tipo de experiencias. A través de estas aportaciones se puede comprender el concepto de valorización turística del patrimonio industrial aplicado en España.

Benito del Pozo (2002), por ejemplo, realiza una síntesis de las principales experiencias de rehabilitación del patrimonio industrial llevadas a cabo atendiendo a la naturaleza de su reconversión (industrial, centros de empresas, operaciones urbanísticas, desarrollo local, etc.). De igual modo analiza algunas de las experiencias más representativas de valorización turística del patrimonio industrial como el Museo de la Minería de El Entrego (Asturias), el Parque Minero de Riotinto (Huelva) (Figura 2) o el Museo Regional de la Minería de Castilla y León (León). Continuando con esta pers- 
Antonio J. Palacios García; Carmen Hidalgo Giralt
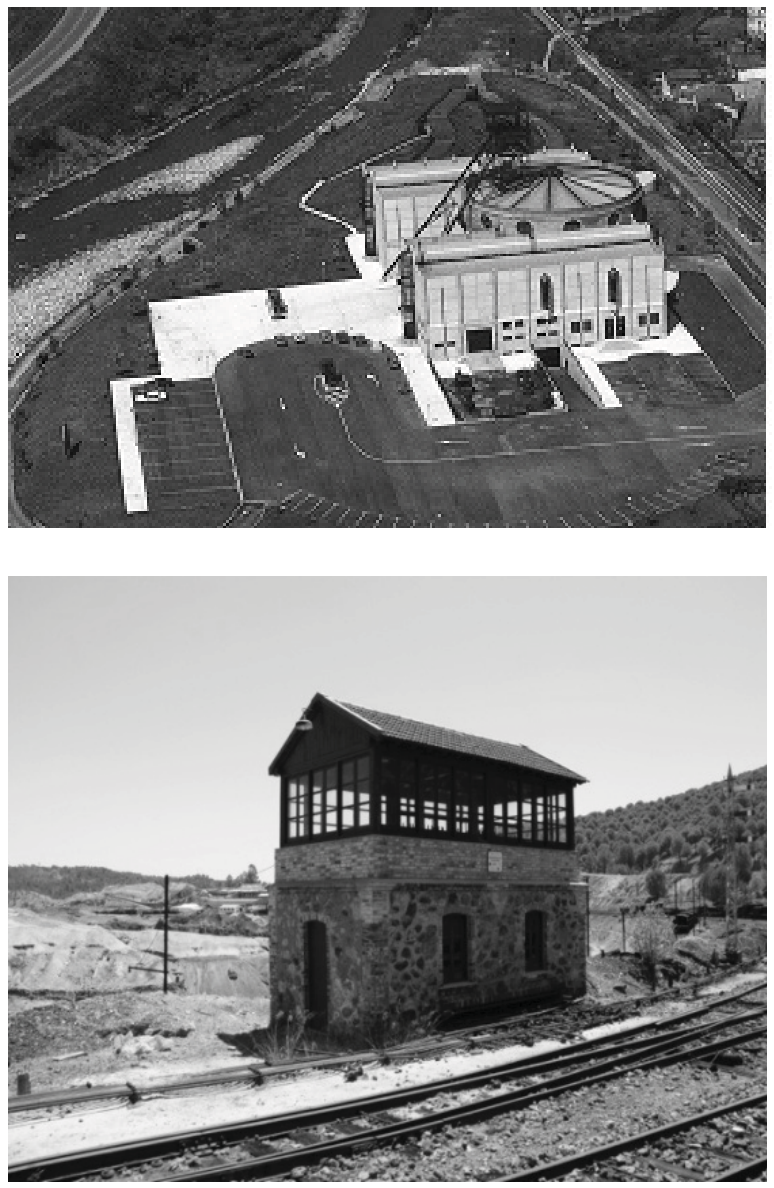

Figura 2 - Museo de El Entrego (Asturias) y Parque Minero de Riotinto (Huelva)

Fuente: Elaboración propia

pectiva general, hay que señalar el artículo de Valenzuela et al. (2008) donde se analizan minuciosamente los éxitos y fracasos de las políticas de intervención sobre el patrimonio minero en cuatro comarcas de ámbito rural altamente desfavorecidas (El Bierzo, Montaña Palentina, Guadix y las Cuencas Mineras Turolenses).

Junto a estos planteamientos generales, hay otras aportaciones que, aunque centradas en experiencias locales, complementan la perspectiva general. Tal es el caso de las aportaciones de Cañizares (2004 y 2008), que revisa las principales iniciativas llevadas a cabo en cuanto a turismo minero en Castilla-La Mancha: la Cueva-Mina del Hierro (Cuenca), el Parque Minero de Almadén (Ciudad Real) (Figura 3) y el
Museo de la Minería de Puertollano (Ciudad Real). En la comarca de la Montaña Palentina hay que destacar los estudios de Gil de Arriba (1999) sobre las nuevas vías para desarrollo sostenible y turismo minero en esta área, especialmente, en Barruelo de Santullán (Figura 3). De igual modo, hay que destacar las aportaciones de Álvarez (2001) al desarrollo del turismo industrial asturiano como estrategia de desarrollo territorial y de Benito del Pozo (2004) sobre el patrimonio industrial de León. Existen otras aportaciones interesantes que analizan las experiencias de puesta en valor desde un punto de vista turística en forma de rutas culturales. Pardo (2004) clasifica los itinerarios en cuatro categorías (rutas urbanas, comarcales, regionales y temáticas) y ofrece casos representativos, nacionales e internacionales, de esa modalidad turística (presta especial atención a las rutas creadas en Cataluña). Uno de los ejemplos más interesantes de producción científica centrada en esta temática es la publicación "Rutas Culturales y Turísticas del Patrimonio Industrial", editada por INCUNA en 2004, donde se analizan rutas europeas, iberoamericanas y españolas.

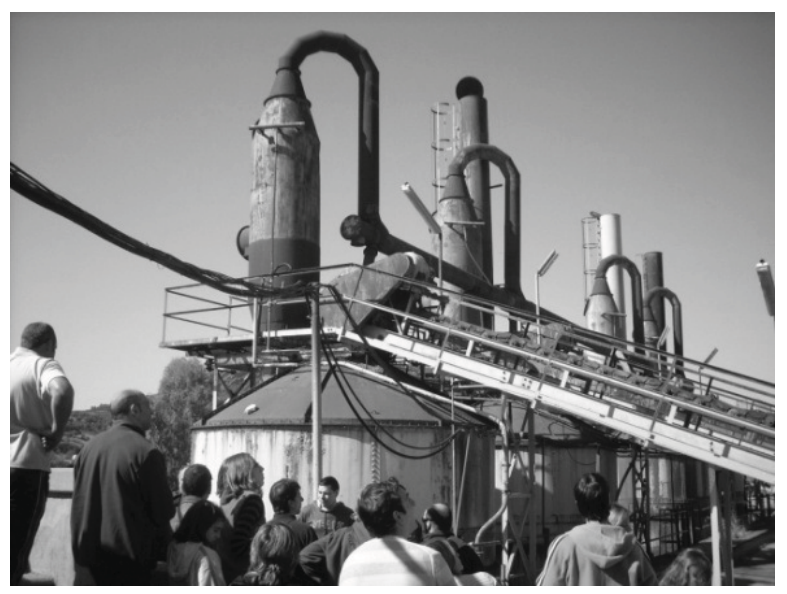




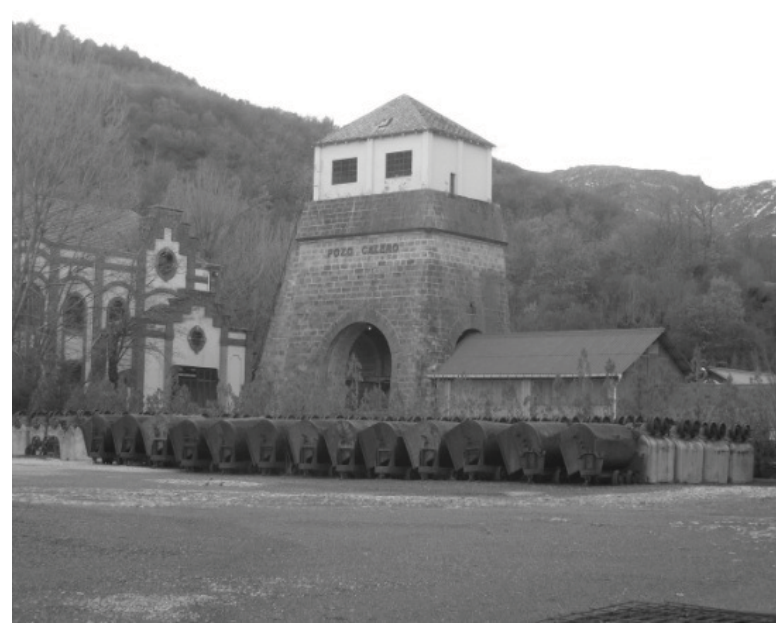

Figura 3 - Parque Minero de Almadén (Ciudad Real) y Centro de Interpretación de Barruelo de Santullán (Palencia)

Fuente: Elaboración propia

Aunque España se ha incorporado tardíamente al estudio del patrimonio industrial, la bibliografía se ha incrementando considerablemente en los últimos años. A pesar de que se trata de estudios de casos muy específicos se pueden extraer de todos ellos líneas generales entre las que destaca el valor cultural del patrimonio industrial y la dotación de usos turísticos como opción de desarrollo económico de territorios afectados por la crisis de la industrialización.

\section{CONCLUSIONES}

El análisis bibliográfico realizado a lo largo de este artículo permite hacer hincapié a modo de conclusión en los siguientes aspectos:

Las aportaciones bibliográficas relacionadas con el patrimonio industrial son realmente recientes en comparación con las realizadas sobre otros elementos culturales debido a que la valorización del patrimonio industrial sólo ha sido posible a partir de la segunda mitad del siglo XX como consecuencia de la desafectación de los espacios industriales. No obstante, en los últimos años se está incrementando considerablemente la bibliografía como consecuencia del interés que está despertando entre diferentes disciplinas científicas.

La bibliografía relacionada con la valorización turística del patrimonio industrial es realmente escasa a pesar de que es un término comúnmente utilizado en la literatura científica. Apenas existen artículos centrados en este proceso y mucho menos publicaciones más específicas. Por lo tanto, los conceptos teóricos no están consensuados y la utilización del concepto "valorización turística del patrimonio industrial" suele estar vacía de contenido.

Los organismos internacionales han desarrollado un verdadero corpus teórico sobre el patrimonio industrial que, en la actualidad, es un excelente referente. Sin embargo, en lo tocante a las aportaciones sobre la valorización turística del patrimonio industrial son las de los especialistas las más interesantes puesto que, huyendo de aspectos generales, se centran en actuaciones concretas de rehabilitación del patrimonio industrial en un determinado territorio.

En el caso español, el estudio del patrimonio industrial ha sido más tardío que otros países europeos; no obstante, en los últimos años la bibliografía se ha incrementado considerablemente. Aunque ésta se centra fundamentalmente en estudios de casos particulares, se extraen líneas generales que apuntan a la valorización turística como una excelente alternativa para el patrimonio industrial desafectado.

Atendiendo a estos criterios, es de destacar la necesidad de que los organismos internacionales y los expertos en patrimonio industrial consensuen el alcance y el significado de los conceptos relacionados con el patrimonio industrial, especialmente los vinculados a su valorización turística. 
Antonio J. Palacios García; Carmen Hidalgo Giralt

\section{REFERENCIAS}

ÁLVAREZ ARECES, M. A. Asturias: patrimonio y turismo industrial. Revista de Cultura y Ciencias Sociales, n. 19, 1998.BENEJAM, Pilar. "Los objetivos de las salidas". Íber, nº 36, p. 7-12, 2003.

BEAUDET, G.; LUNDGREN, J. O. Le tourisme industriel et la ressource patrimoniale: en user sans en abuser. Téoros: 1996.

BENITO DEL POZO, C. Europa ante el patrimonio industrial. Revista Asturiana de Economía, n. 6, 1996.

BENITO DEL POZO, P. Patrimonio industrial y la cultura del territorio. Boletín de la Asociación de Geógrafos Españoles, n. 34, 2002.

Luces y sombras en el patrimonio industrial de León. In: ÁLVAREZ ARECES, M. A. Rutas culturales y turísticas del patrimonio industrial. Gijón: CICEES, 2004.

BÖHMER, A. Rhône-Alpes, terre de prédilection de l'industrie. Cahier Espaces, n. 57, 1998.

CAÑIZARES RUIZ, M. C. Algunas iniciativas de turismo minero en Castilla-La Mancha. Cuadernos Geográficos, n. 34, 2004.

El atractivo turístico de una de las minas de mercurio más importantes del mundo: el Parque Minero de Almadén (Ciudad Real). Cuadernos de Turismo, n. 21, 2008.

CAPEL, H. El turismo industrial y el patrimonio histórico de la electricidad. Scripta Vetera. Revista Electrónica de Geografía y Ciencias Sociales, 1996. Disponível em: < http://www.ub.es/geocrit/sv14.htm >.

CASANELLES I RAHOLA, E. Por unos museos de ciencia y tecnología In: II Jornadas Sobre La Protección Y Revalorización Del Patrimonio Industrial, 1998.

COLE, D. Exploring the sustainability of mining heritage tourism. Journal of sustainable tourism, v. 12, n. 6.
CORNU, P. Pour un tourisme indsutriel et technique enfin adulte. Cahier Espaces, n. 57.

COUSIN, S. Le tourisme industriel, objet médiatique non identifié. Cahier Espaces, n. 57.

DAMIEN, M. M.; SOBRY, C. Le tourisme industriel: le tourisme du savoir faire? París: L'Harmattan, 2001.

EDWARDS, A.; LLURDÉS I COIT, J. C. Mines and quarries. Annals of Tourism Research, v. 23, n. 2, p. 341-362, 1996.

FILIPE, G. Patrimonio Industrial, experiencias museológicas y proyectos de intervención en el territorio. In: ÁLVEREZ ARECES, M. A. Estructuras y paisajes industriales: proyectos socioculturales $y$ turismo industrial. Gijón: CICEES, 2003.

FLACHS, S. Les visites du jeudi. Cahier Espaces, n. 50, p. 50-51, 1998.

FLEITES VELAZCO, R. Antiguo ingenio azucarero Tahoro y su entorno. Ábaco, n. 19, p. 18-22, 1998.

FORNER MUÑOZ, S. Arqueología y patrimonio industrial. Canelobre, n. 16, p. 18-32, 1989.

FRITZ-NEMETH, P.; LUNDGREN, J. O. Tourist attractions: from natural to industrial. Téoros, $\mathrm{p}$. 23-30, 1996.

GIL DE ARRIBA, C. Turismo rural y nuevas vías para un desarrollo sostenible en la Montaña Palentina: el reto de una aparente antinomia. In: CAVERO DIÉGUEZ, V. et. al. El medio rural español: cultura, paisaje y naturaleza. Salamanca: Ediciones Universidad de Salamanca, 1999.

GOUBARD, M. Tourisme industriel et promotion d'un territoire. Cahier Espaces, n. 57, p. 66-69, 1998.

HERNÁNDEZ HERNÁNDEZ, F. Manual de museología. Madrid: Síntesis, 1998.

HEVIA MARTÍNEZ, A. Cervecería Pedro Marrero La Tropical. Ábaco, n. 19, p. 7-12, 1999.

HUDSON, K. World industrial archeology. Cambridge: Cambridge University Press, 1979. 
JACOMY, B. El Ecomuseo de Creusot: Montceaules Mines - balance de diez años de actividad. In: I Jornadas Sobra La Protección Y Revalorización Del Patrimonio Industrial, 1984.

JANSEN-VERBEKE, M. Industrial heritage: a nexus for sustainable tourism development. Tourism Geographies, n. 1, p. 70-85, 1999.

LECLERCQ, I. Nord-Pas-de-Calais: une action concertée en faveur du tourisme industriel. Cahier Espaces, n. 57, p. 34-37, 1998. p. 70-85

LOPES CORDEIRO, J. M. La arquitectura industrial en Portugal. Ábaco, v. 2, n. 19, p. 35-44, 1998.

LLURDÉS I COIT, J. C. El turismo industrial y la estética de los paisajes en declive. Estudios Turísticos, n. 212, p. 91-107, 1994.

Patrimonio industrial y patrimonio de la humanidad: el ejemplo de las colonias textiles catalanas - potencialidades turísticas y algunas reflexiones. Boletín de la Asociación de Geógrafos Españoles, n. 28, p. 147-160, 1999.

MARAVAL, J. P. Un outil decommunication territoriale. Cahier Espaces, n. 57, p. 43-49, 1998.

MASSÉ, M. Tourisme industriel, technique et scientifique. Cahier Espaces, n. 57, p. 26-29, 1998.

OTGAAR, A. et. al. Industrial tourism: opportunities for city and enterprise, Rotterdam: EURICUR, 2008.

PARDO ABAD, C. J. La reutilización del patrimonio industrial como recurso turístico: aproximación geográfica al turismo industrial. Treballs de la Societat Catalana de Geografía, n. 57, 2004. p. 7-32

PERERA ESCALONA, A. Locomotoras a vapor, un patrimonio vivo en Cuba. Ábaco, n. 19, p. 3-6, 1998.

PERRAULT, G. Géologie, mines et tourisme en Abitibi-Témiscamingue. Téoros, p. 31-35, 1996.

PINARD, J. L'aecheologie industrielle au service du tourisme. Problems of Tourism, v. 1 n. 35, p. 62-72, 1987.

PREITE, M. La reutilización del patrimonio minero en la Toscana. In: ÁLVAREZ ARECES, M. A. Patrimonio industrial: lugares de la memoria. Gijón: CICEES, 2002.

VALENZUELA, M. Turismo y patrimonio utilitario: el discreto encanto de las actividades decadentes. In: VALENZUELA, M. (Coord.). Un mundo por descubrir en el Siglo XXI. Madrid: Real Sociedad Geográfica, 2003.

VALENZUELA, M.; PALACIOS, A.; HIDALGO, C. La valorización turística del patrimonio minero en entornos rurales desfavorecidos: actores y experiencias. Cuadernos de Turismo, n. 22, p. 231-260, 2008.

VIAENE, P. Conservación, restauración, recuperación del patrimonio hullero en Bélgica. Un intento de hacer balance. Ábaco, n. 19, p. 45-59, 1998.

VIÑUALES, G. M. Panorama del patrimonio industrial en Iberoamérica. In: ÁLVAREZ ARECES, M. A. Rutas culturales y turísticas del patrimonio industrial. Gijón: CICEES, 2004.

Recebido em 07/08/2009

Aceito para publicação em 10/10/2009 